\title{
Initial single-centre Canadian experience with 18F-fluoromethylcholine positron emission tomography-computed tomography (18F-FCH PET/ (T) for biochemical recurrence in prostate cancer patients initially treated with curative intent
}

\author{
Simon Gauvin, MD; ${ }^{* 1}$ Yannick Cerantola, MD; ${ }^{* 2,3}$ Eléonore Haberer, ${ }^{1,2}$ Vincent Pelsser, MD; ${ }^{1}$ \\ Stephan Probst, MD; ${ }^{; 4}$ Franck Bladou, MD; Maurice Anidjar, $\mathrm{MD}^{+2}$
}

${ }^{\star}$ Co-first authors; ${ }^{\dagger}$ co-senior authors

'Department of Radiology, Jewish General Hospital, McGill University Health Centre, Montreal, QC, Canada; ${ }^{2}$ Department of Urology, Jewish General Hospital, Montreal, QC, Canada; ${ }^{2}$ Department of Urology, University Hospital of Lausanne, Switzerland; ${ }^{4}$ Department of Nuclear Medicine, Jewish General Hospital, Montreal, QC, Canada

Cite as: Can Urol Assoc J 2017;11 (1-2):47-52. http://dx.doi.org/10.5489/cuaj.4068

\section{Abstract}

Introduction: We sought to determine predictive factors (patient and prostate-specific antigen [PSA] characteristics) for 18F-fluoromethylcholine positron emission tomography-computed tomography (18F-FCH PET/ $\mathrm{CT})$ positivity in the context of biochemical recurrence after local treatment of prostate cancer (PCa) with curative intent.

Methods: This is a retrospective study including $6018 \mathrm{~F}-\mathrm{FCH}$ PET/ CT scans of patients with biochemical recurrence after initial radical prostatectomy (RP), external beam radiation therapy (EBRT), or focal high-intensity focused ultrasound (HIFU) with curative intent. The results were compared to findings on magnetic resonance imaging $(\mathrm{MRI})$, computed tomography $(\mathrm{CT})$, bone scan (BS), and histological analysis when available. Univariate analysis was performed to correlate results with patient characteristics.

Results: Thirty-eight (63.3\%) scans were positive, 17 (28.3\%) negative, and $5(8.3 \%)$ equivocal. Of the positive scans, $16 \mathrm{dem}$ onstrated local recurrence, 12 regional/distant lymph nodes, five bone metastasis, and five local and distant recurrences. Among the $22 \mathrm{PET} / \mathrm{CTs}$ showing metastasis, conventional imaging was performed in 16 patients $(72.7 \%)$. Of these, it demonstrated the lesion(s) found on PET/CT in eight patients (50.0\%), was negative in seven $(43.8 \%)$, and equivocal in one $(6.3 \%)$. The trigger PSA $(p=0.04)$, prostate-specific antigen velocity (PSAV) $(p=0.03)$, and prostate-specific antigen doubling time (PSADT) $(p=0.046)$ were significantly different when comparing positive and negative scans. Patients with positive scans were more likely to have received EBRT initially (odds ratio [OR] 11.0, 95\% confidence interval [CI] 2.2-55.3). A trigger PSA of $2.6 \mathrm{ng} / \mathrm{mL}$ had a sensitivity of $84 \%$ and specificity of $65 \%$ for a positive scan. PET/CT changed the clinical management plan in 17 patients $(28.3 \%)$.

Conclusions: 18F-FCH PET/CT demonstrates a high detection rate for local and distant recurrences after localized PCa treatment. A trigger PSA above $2.6 \mathrm{ng} / \mathrm{mL}$ seems optimal for appropriate patient selection.

\section{Introduction}

Prostate adenocarcinoma ( $\mathrm{PCa}$ ) is the most common cancer among Canadian men. The lifetime risk of developing prostate cancer is one in eight and the lifetime risk of dying from it is one in 27. ${ }^{1}$ Treatment options for localized PCa include active surveillance in low-risk cancer, and radical prostatectomy (RP), external beam radiation therapy (EBRT), and in some instances, focal therapy — such as high-intensity focused ultrasound (HIFU) - in intermediate-risk disease. ${ }^{2-4}$ High-risk disease is treated by surgery or a combination of radiation therapy and androgen-deprivation therapy (ADT). Recurrence after treatment is not uncommon, occurring in approximately $20-30 \%$ of patients with RP and $20-50 \%$ of patients after EBRT. $5-8$

Differentiating between local or metastatic recurrence is of primordial importance in selecting appropriate treatment. Local salvage treatment with curative intent can be offered in case of local recurrence. Systemic palliative treatment with hormonal therapy and/or chemotherapy remains the current standard for patients with metastatic disease. Therapy directed to oligometastases remains controversial, with a small number of studies showing some benefits. ${ }^{9-11}$

Computed tomography (CT) and bone scintigraphy (BS) are widely used as part of initial workup of biochemical recurrence. However, these are limited by poor ability to detect disease at low prostate-specific antigen (PSA) levels. ${ }^{12-15}$ Novel functional imaging techniques have been developed and increasingly studied over the last decade, including 11C-choline and 18F-fluoromethylcholine (18F$\mathrm{FCH}){ }^{16}$ Choline is an essential component of phospholipid membrane and demonstrates increased metabolism in PCa. ${ }^{17}$ The limited short half-life of 11C-choline (20.3 minutes) 


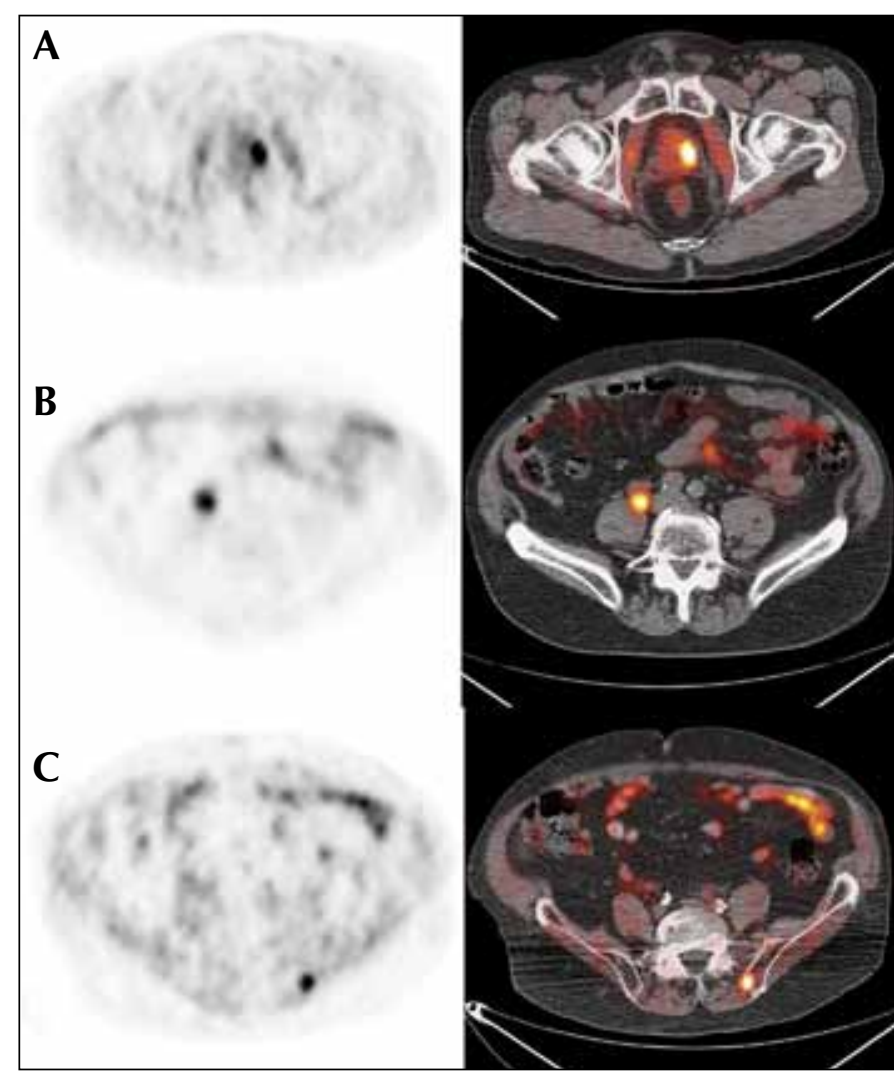

Fig. 1. Examples of positive $18 \mathrm{~F}$-fluoromethylcholine positron emission tomography-computed tomography (18F-FCH PET/CT) scans. (A) Axial 18F-FCH $\mathrm{PET} / \mathrm{CT}$ images obtained from a patient with biochemical recurrence initially treated with external beam radiation therapy (EBRT). Focal uptake in the left prostate is demonstrated (SUV 7.2). The patient subsequently underwent salvage brachytherapy with response in prostate-specific antigen; $(\boldsymbol{B})$ axial $\mathrm{PET} / \mathrm{CT}$ images from a different patient with biochemical recurrence after initial radical prostatectomy demonstrating an enlarged right common iliac lymph node with high uptake (SUV 12.2), consistent with recurrence. Followup imaging later showed complete resolution of lymphadenopathy after the patient received hormonotherapy; (C) axial PET/CT images from another patient with initial EBRT demonstrating increased uptake in the left posterior iliac bone (SUV 8.3), consistent with a bone metastasis.

prompted research into synthesis of $18 \mathrm{~F}-\mathrm{FCH}$ with a longer half-life (109.7 minutes). Although conflicting results have been reported in the course of initial staging of $\mathrm{PCa}, 18 \mathrm{~F}$ $\mathrm{FCH}$ positron emission tomography-computed tomography (PET/CT) has shown promising results for detection of metastasis in the context of biochemical recurrence. ${ }^{16,18-22}$ Recent reports suggest that this functional imaging technique might directly impact the management of these patients. ${ }^{23-25}$

The primary objective of this study was to determine predictive factors (patient and PSA characteristics) for $18 \mathrm{~F}-\mathrm{FCH}$ $\mathrm{PET} / \mathrm{CT}$ positivity in patients with biochemical failure after local treatment for PCa with curative intent. Secondary objectives were to evaluate the impact of PET/CT on patient management and to compare its value to standard imaging techniques.

\section{Methods}

\section{Patients and study design}

This study was approved by the hospital research ethics committee (study \#13-047) and written informed consent was obtained from all patients. We conducted a singlecentre, retrospective analysis including 60 18F-FCH PET/ CT scans (59 patients) performed from March 2014January 2016. Inclusion criteria consisted of: histologically proven $\mathrm{PCa}$, initial treatment with curative intent (RP, EBRT, or HIFU), and biochemical recurrence as defined by the guidelines of the European Association of Urology. ${ }^{26}$ Patients with distant nodal or bone metastases or with nondiagnostic scans were excluded. Patient characteristics are presented in Tables 1 and 2 .

\section{Technique and study interpretation}

PET/CT preparation consisted of four-hour fasting. Approximately $4 \mathrm{MBq} / \mathrm{kg}$ IV of $18 \mathrm{~F}$-fluoromethylcholine (18F-FCH) supplied by the Montreal Neurological Institute (Montreal, QC, Canada) were administered. Studies were performed using a hybrid PET/CT scanner (Discovery ST, General Electric Medical Systems, Waukesha, WI, U.S.). Images were acquired 10-30 minutes post-injection from skull base to thighs (6-7 beds, 3-4 minutes/bed). A nuclear medicine specialist then classified the results as positive, negative, or equivocal; a positive examination was defined as $18 \mathrm{~F}-\mathrm{FCH}$ uptake higher than background activity and not explained by physiological process. Examples of positive 18F-FCH PET/CT findings are provided in Fig. 1.

\section{Validation of results}

PET/CT findings were compared to magnetic resonance imaging (MRI), CT, BS, and histological analysis when available. Validation criteria included: 1) positive histological analysis; 2) response to treatment, defined by decreased PSA after treatment and/or response on followup imaging; 3) progression on followup PET/CT; and 4) positive conventional imaging. All negative PET/CTs were considered false negatives, as they failed to detect the cause of biochemical recurrence.

\section{Impact on clinical management}

A summary of clinical information was provided to two urooncologists, who were not the main treating physicians and were blinded to identifying information, PET/CT results, and information available afterwards. They were then asked to independently determine the theoretical management had 


\begin{tabular}{|c|c|}
\hline Characteristics & Value \\
\hline \multicolumn{2}{|l|}{ Age, years } \\
\hline Mean (SD) & $67.9(9.3)$ \\
\hline Median & 67.9 \\
\hline Range & $43.0-88.5$ \\
\hline \multicolumn{2}{|c|}{ T stage, $n(\%)(N A=5)$} \\
\hline $\mathrm{T} 1$ & $11(18.3)$ \\
\hline $\mathrm{T} 2$ & $29(48.3)$ \\
\hline T3 & $15(25)$ \\
\hline \multicolumn{2}{|c|}{$\mathrm{N}$ stage, $\mathrm{n}(\%)(\mathrm{NA}=3)$} \\
\hline $\mathrm{Nx}$ & $16(26.7)$ \\
\hline No & $35(58.3)$ \\
\hline N1 & $6(10.0)$ \\
\hline \multicolumn{2}{|c|}{ Gleason score, $n(\%)(N A=3)$} \\
\hline 6 & $6(10.0)$ \\
\hline 7 & $31(51.7)$ \\
\hline$\geq 8$ & $20(33.3)$ \\
\hline \multicolumn{2}{|c|}{ Initial treatment, $\mathrm{n}(\%)$} \\
\hline $\mathrm{RP}$ & $33(55.0)$ \\
\hline EBRT & $26(43.3)$ \\
\hline Focal HIFU & $1(1.7)$ \\
\hline \multicolumn{2}{|c|}{ Other treatments, $n(\%)(N A=1)$} \\
\hline Yes & $21(35.0)$ \\
\hline No & $38(63.3)$ \\
\hline \multicolumn{2}{|c|}{$\begin{array}{l}\text { Margin status in patients post-RP, } n(\%) \\
(\mathrm{NA}=3)\end{array}$} \\
\hline Positive & $13(39.4)$ \\
\hline Negative & $17(51.5)$ \\
\hline \multicolumn{2}{|c|}{$\begin{array}{l}\text { Time from end of initial treatment to } \\
P E T / C T \text {, years }(N A=1)\end{array}$} \\
\hline Mean (SD) & $5.5(3.4)$ \\
\hline Median & 5.6 \\
\hline Range & $0.1-14.3$ \\
\hline \multicolumn{2}{|c|}{ ADT at time of the PET/CT, $n(\%)(N A=2)$} \\
\hline Yes & $8(13.3)$ \\
\hline No & $50(83.3)$ \\
\hline
\end{tabular}

the PET/CT not been performed. Finally, the theoretical and actual therapeutic strategies were compared.

\section{Statistical analysis}

All statistical analyses were performed using SAS (v.9.4) (SAS Institute Inc., Cary, NC, U.S.). For descriptive statistics, we computed t-test for continuous variables or performed oneway ANOVA. Results with $p<0.05$ were considered statistically significant. The Chi-square test for proportions and Fisher exact test were calculated when necessary. Finally, we modeled the probability of having a positive scan using PROC LOGISTIC.

\section{Table 2. Patient PSA characteristics}

\begin{tabular}{lc}
\hline Characteristics & Value \\
\hline PSA at diagnosis, $\mathrm{ng} / \mathrm{mL}(\mathrm{NA}=5)$ & $13.6(12.3)$ \\
Mean (SD) & 9 \\
Median & $4.0-59.3$ \\
Range & \\
PSA nadir, ng/mL (NA=3) & $1.1(2.0)$ \\
Mean (SD) & 0.2 \\
Median & $0.0-9.5$ \\
Range & \\
Trigger PSA, ng/mL (NA=1) & $8.0(11.7)$ \\
Mean (SD) & 3.9 \\
Median & $0.2-56.6$ \\
Range & \\
PSADT, months (NA=5) & $9.9(9.4)$ \\
Mean (SD) & 6.2 \\
Median & $1.2-36.0$ \\
Range & \\
PSAV, ng/mL/year (NA=5) & $7.6(14.3)$ \\
Mean (SD) & 2.2 \\
Median & $0.1-79.0$ \\
Range &
\end{tabular}

NA: not available; PSA: prostate-specific antigen; PSADT: prostate-specific antigen doubling time; PSAV: prostate-specific antigen velocity; SD: standard deviation.

\section{Results}

\section{$\mathrm{PEE} / \mathrm{CT}$ results and sites of recurrence}

Sixty examinations were performed at a median PSA of 3.9 $\mathrm{ng} / \mathrm{mL}$. Of these, 38 (63.3\%) PET/CT scans were positive, 17 $(28.3 \%)$ negative, and five ( $8.3 \%)$ equivocal/indeterminate. Of the 38 positive scans, 16 demonstrated local recurrence (14 in patients with initial EBRT, one RP, and one HIFU), 12 regional and/or distant lymph nodes (10 RP, two EBRT), five bone metastasis, and five local and distant recurrences.

\section{Lesion-based validation of $\mathrm{PET} / \mathrm{CT}$ results}

Fifteen $(71.4 \%)$ of the positive scans for local recurrence $(n=21)$ were validated according to histological analysis in 10 patients $(66.7 \%)$, response to treatment as defined by a decrease in PSA in two patients (13.3\%), and correlation with conventional imaging in three patients $(20.0 \%)$. One scan was a biopsy-proven false positive.

Eighteen $(81.8 \%)$ of the positive scans for metastasis $(n=22)$ were validated according to a response to treatment on following imaging studies in eight patients (44.4\%), a response to treatment (decreased PSA) in five patients $(27.8 \%)$, correlation with conventional imaging in four patients $(22.2 \%)$, and progression on followup PET/CT in one patient $(5.6 \%)$. One scan was considered false positive after comparison with conventional imaging. 
Gauvin et al.

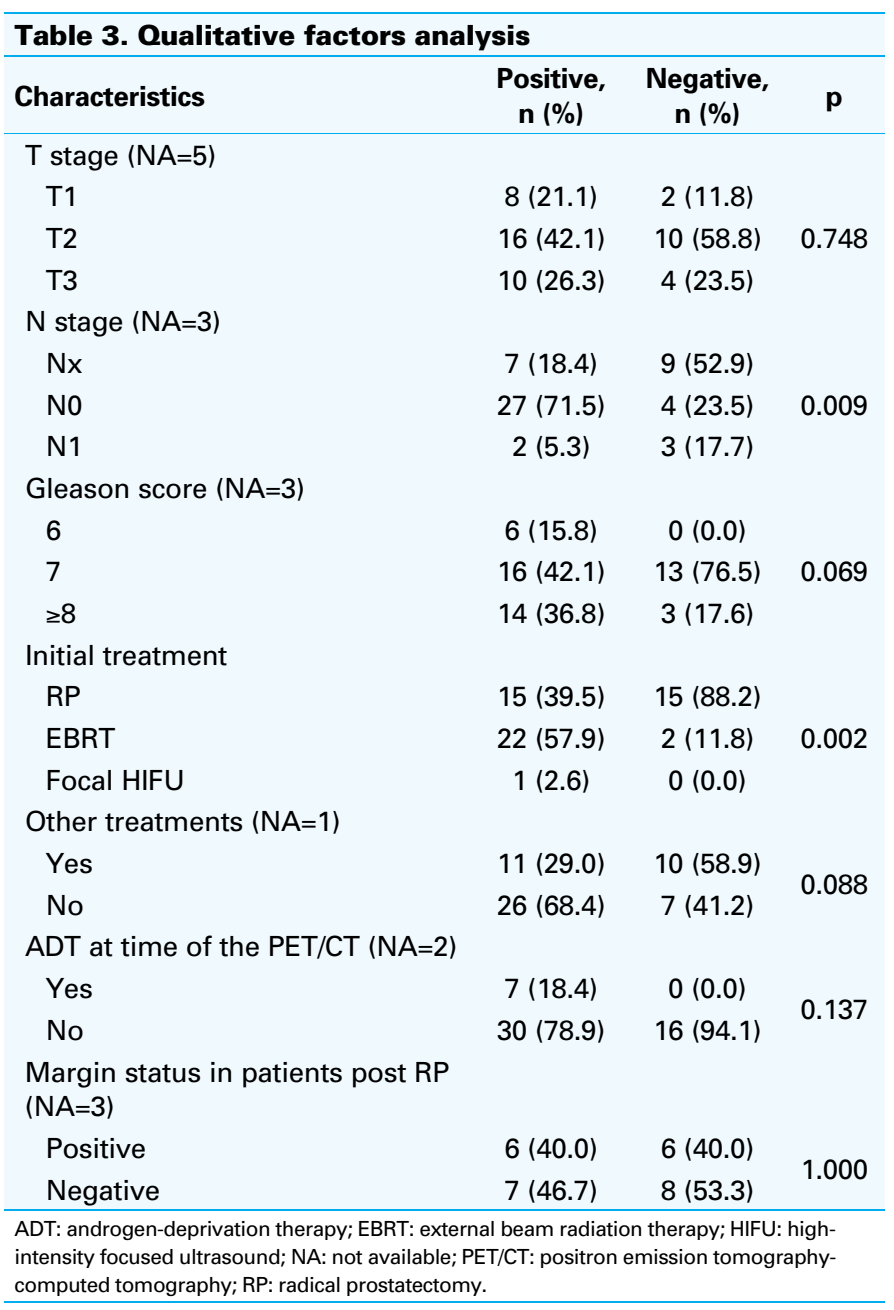

One local, two nodal, and one bone recurrence were missed by $\mathrm{PET} / \mathrm{CT}$.

\section{Comparison with conventional imaging modalities}

Among the $21 \mathrm{PET} / \mathrm{CT}$ s showing local recurrence, prostate MRI was performed in 11 patients (52.4\%). Of these, 10 were positive (90.9\%) and 1 was equivocal $(9.1 \%)$.

Table 4. Quantitative factors analysis

\begin{tabular}{lccc}
\hline Characteristics & $\begin{array}{c}\text { Positive, } \\
\text { mean (SD) }\end{array}$ & $\begin{array}{c}\text { Negative, } \\
\text { mean (SD) }\end{array}$ & p \\
\hline Age, years & $69.6(8.6)$ & $64.6(9.3)$ & 0.061 \\
Time from end of initial & $5.9(3.1)$ & $5.7(3.9)$ & 0.875 \\
treatment to PET/CT, years & & & \\
PSA at diagnosis, ng/mL & $12.7(11.3)$ & $15.0(7.6)$ & 0.525 \\
PSA nadir, ng/mL & $1.2(2.0)$ & $0.9(2.3)$ & 0.559 \\
Trigger PSA, ng/mL & $10.9(6.4)$ & $3.5(0.5)$ & 0.035 \\
PSADT, months & $8.2(7.6)$ & $13.9(12.0)$ & 0.046 \\
PSAV, ng/mL/year & $11.1(17.0)$ & $1.9(4.4)$ & 0.032 \\
\hline
\end{tabular}

PET/CT: positron emission tomography-computed tomography; PSA: prostate-specific antigen; PSADT: prostate-specific antigen doubling time; PSAV: prostate-specific antigen velocity; SD: standard deviation.

\begin{tabular}{|c|c|c|c|c|}
\hline Characteristics & $\begin{array}{c}\text { Positive, } \\
\text { n (\%) }\end{array}$ & $\begin{array}{c}\text { Negative, } \\
\text { n (\%) }\end{array}$ & $\begin{array}{l}\text { Crude } \\
\text { odds } \\
\text { ratio }\end{array}$ & $95 \% \mathrm{Cl}$ \\
\hline $\begin{array}{l}\text { Number of PET/CT } \\
\text { scans }\end{array}$ & 38 & 17 & & \\
\hline Initial treatment RP & $15(39.5)$ & $15(88.2)$ & 1.0 & Ref. \\
\hline Initial treatment EBRT & $22(57.9)$ & $2(11.8)$ & 11.0 & $2.2-55.3$ \\
\hline Trigger PSA $<2 \mathrm{ng} / \mathrm{mL}$ & $3(7.9)$ & $9(52.9)$ & 1.0 & Ref. \\
\hline Trigger $\mathrm{PSA} \geq 2 \mathrm{ng} / \mathrm{mL}$ & $34(89.5)$ & $8(47.1)$ & 12.8 & $2.8-58.1$ \\
\hline PSAV <1 ng/mL/year & $4(10.5)$ & $11(64.7)$ & 1.0 & Ref. \\
\hline $\begin{array}{l}\mathrm{PSAV} \geq 1 \text { but }<5 \mathrm{ng} / \\
\mathrm{mL} / \text { year }\end{array}$ & $14(36.8)$ & $5(29.4)$ & 7.7 & $1.7-35.7$ \\
\hline PSAV $\geq 5 \mathrm{ng} / \mathrm{mL} /$ year & $16(42.1)$ & $1(5.9)$ & 44.0 & $4.3-448.3$ \\
\hline
\end{tabular}

Among the $22 \mathrm{PET} / \mathrm{CT}$ scans showing metastatic disease, conventional imaging was performed in 16 patients $(72.7 \%)$. Of these, conventional imaging demonstrated the lesion(s) found on PET/CT in eight patients (50.0\%), was negative in seven $(43.8 \%)$, and equivocal in one $(6.3 \%)$.

\section{Correlation between patient characteristics and PET/CT results}

More patients with a positive scan were initially treated with EBRT $(p=0.002)$. Moreover, there was a significant difference between trigger PSA, prostate-specific antigen velocity (PSAV), and prostate-specific antigen doubling time (PSADT) when comparing positive and negative PET/CTs (Tables 3, 4, and 5).

Thirty-four patients (89.5\%) with a positive PET/CT ( $n=38)$ had a trigger $\mathrm{PSA} \geq 2 \mathrm{ng} / \mathrm{mL}$, three $(7.9 \%) 1-2 \mathrm{ng} / \mathrm{mL}$, and none $(0 \%)<1 \mathrm{ng} / \mathrm{mL}$. PET/CT was positive in $77 \%, 60 \%$, and $0 \%$ for patients with a trigger PSA $\geq 2 \mathrm{ng} / \mathrm{mL}, 1-2 \mathrm{ng} /$ $\mathrm{mL}$, and $<1 \mathrm{ng} / \mathrm{mL}$, respectively.

There was no statistically significant relationship between maximum standardized uptake values (SUVmax) and Gleason scores $(p=0.27)$ or trigger PSA $(p=0.14)$.

A trigger PSA of $2.6 \mathrm{ng} / \mathrm{mL}$ and PSADT of 4.4 months had a sensitivity of $84 \%$ and $76 \%$ and specificity of $65 \%$ and $50 \%$, respectively for a positive scan (Fig. 2 ).

\section{Impact on clinical management}

The theoretical and actual management plans differed in 17 cases $(28.3 \%), 11$ of which with positive PET/CT. The treatment plan changed from watchful waiting to treatment in seven cases and from treatment to watchful waiting in four cases. In six cases, the therapeutic strategy was modified; two of these involved converting palliative to a curative intent salvage treatment. 


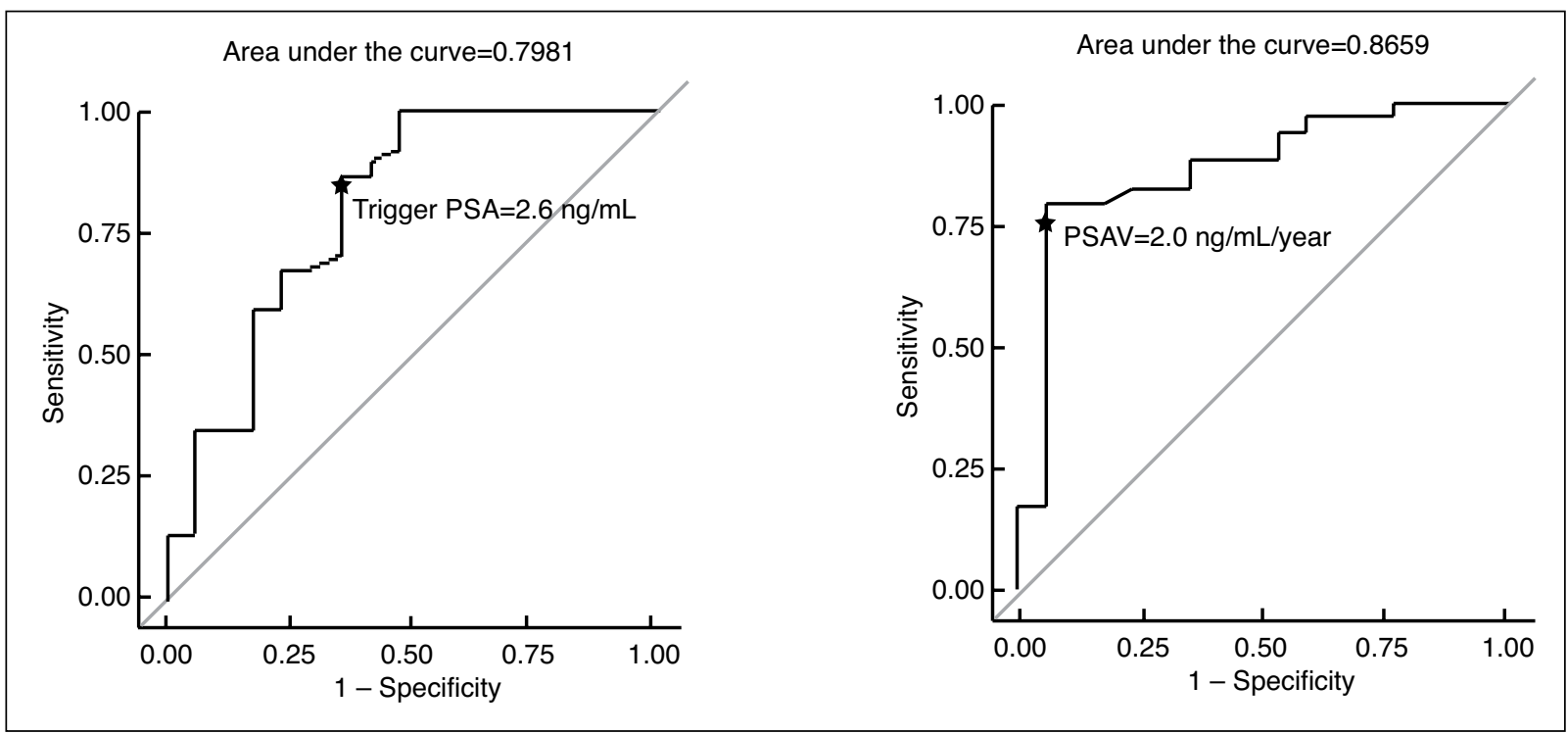

Fig. 2. Trigger prostate-specific antigen (PSA) and PSA velocity (PSAV) receiver operating characteristic (ROC) curves.

\section{Discussion}

In this study, we report our initial local experience with $18 \mathrm{~F}$ $\mathrm{FCH}$ PET/CT in the context of PCa biochemical recurrence after treatment with curative intent.

Reported detection rates for $18 \mathrm{~F}-\mathrm{FCH}$ PET/CT vary from $38-98 \%$. This is probably related to heterogeneous study groups. Our study shows a detection rate of $63.3 \%$ for recurrence after localized treatment of $\mathrm{PCa}$, similar to previous studies. ${ }^{27,28} \mathrm{~A}$ large number of the positive PET/CTs were validated using pre-established criteria.

PSA parameters were significantly different when comparing positive and negative PET/CT results, which confirms the known relationship with PSA kinetics. ${ }^{27,29-31}$ We found the best threshold values to predict PET/CT positivity to be a trigger PSA of $2.6 \mathrm{ng} / \mathrm{mL}$, PSAV of $2.0 \mathrm{ng} / \mathrm{mL} /$ year, and PSADT of 4.4 months. In comparison, Rodado-Marina et al reported a trigger PSA of $3.5 \mathrm{ng} / \mathrm{mL}$ (sensitivity $64 \%$, specificity $76 \%$ ) and PSADT of six months (sensitivity $58 \%$, specificity $58 \%$ ) while Cimitan et al reported a sensitivity of $79.5 \%$ and specificity of $67 \%$ for a trigger PSA of $2 \mathrm{ng} / \mathrm{mL} .^{27,30}$

Initial Gleason score was not significantly different between patients with positive and negative PET/CT $(p=0.069)$. This could possibly be related to our small sample size. In a larger study, Cimitan et al demonstrated that a Gleason score $\geq 7$ was an independent predictive factor for positive $\mathrm{PET} / \mathrm{CT}$, even with a low trigger PSA. ${ }^{30}$

We did not find ADT administration at the time of the scan to negatively affect the detection rate, which is consistent with Chondrogiannis et al. ${ }^{31}$

In our study, PET/CT did not add significant value to the MRI diagnosis in context of local recurrence. In fact, pelvic MRI remains the modality of choice, with a sensitivity as high as $91 \%$ in the context of biochemical recurrence after RP. ${ }^{32,33}$ Interestingly, 18F-FCH PET/CT detected extraprostatic disease not identified by conventional imaging in seven patients $(43.8 \%)$.

More specific markers have been developed to increase detection rates of biochemical recurrence. In a study including 125 patients, Bluemel et al found that ${ }^{68} \mathrm{Ga}$-PSMA PET/ CT detected location of recurrences in $43.8 \%$ of cholinenegative patients..$^{34}$ In a study including 319 patients, AfsharOromieh et al determined that ${ }^{68} \mathrm{Ga}$-PSMA PET/CT was positive in $92.3 \%, 71.8 \%$, and $52.9 \%$ of cases when PSA $>2$ $\mathrm{ng} / \mathrm{mL}, 1-2 \mathrm{ng} / \mathrm{mL}$, and $\leq 1 \mathrm{ng} / \mathrm{mL}$, respectively. ${ }^{35}$ Therefore, when compared to our results, ${ }^{68} \mathrm{Ga}$-PSMA PET/CT has a higher detection rate and is positive at lower PSA values than 18F-FCH PET/CT.

We found that PET/CT had an impact on clinical management in 17 patients $(28.3 \%)$, in the context of biochemical recurrence. This is lower than in other studies, which showed a change of treatment plan in $48-55 \%$ of patients. ${ }^{23,24}$ These studies used retrospective questionnaires completed by treating physicians and were not blinded, in contrast to our study. This could possibly explain the difference between results.

Our study remains limited by its retrospective design and relatively small sample size. Nevertheless, to the best of our knowledge, our study cohort represents the largest Canadian PCa patient group studied so far.

\section{Conclusion}

In conclusion, 18F-FCH PET/CT demonstrates a high detection rate for local, as well as distant recurrences after localized PCa treatment with curative intent. A trigger PSA above $2.6 \mathrm{ng} / \mathrm{mL}$ seems optimal for appropriate patient selection. 
Gauvin et al.

Further studies are needed to better understand the role of $18 \mathrm{~F}-\mathrm{FCH} \mathrm{PET} / \mathrm{CT}$ in the management of PCa patients.

Competing interests: Dr. Probst has been an advisor for Bayer and has participated in a clinical trial for Progenics. The remaining authors report no competing personal or financial interests.

This paper has been peer-reviewed.

\section{References}

1. Cancer.ca. Canadian Cancer Society's Advisory Committee on Cancer Statistics; 2015 [updated 2015; cited 2016 February 17]. hittp://www.cancer.ca/. Accessed February 17, 2016.

2. Heidenreich A, Bastian PJ, Bellmunt J, et al. EAU guidelines on prostate cancer. Part 1: screening, diagnosis, and local treatment with curative intent-update 2013. Eur Urol 2014;65:124-37. https://doi.org/10.1016/i.eururo.2013.09.046

3. Shah $\Pi$, Kasivisvanathan V, Jameson C, et al. Histological outcomes after focal high-intensity focused ultrasound and cryotherapy. World J Urol 2015;33:955-64. https://doi.org/10.1007/s00345-015-1561-0

4. Valerio $M$, Ahmed HU, Emberton $M$, et al. The role of focal therapy in the management of localised prostate cancer: A systematic review. Eur Urol 2014;66:732-51. https://doi.org/10.1016/i.eururo.2013.05.048

5. Han $M$, Partin AW, Pound CR, et al. Long-term biochemical disease-free and cancer-specific survival following anatomic radical retropubic prostatectomy. The 15-year Johns Hopkins experience. Urol Clin North Am 2001;28:555-65. https://doi.org/10.1016/S0094-0143(05)70163-4

6. Stephenson AJ, Scardino PT, Eastham JA, et al. Preoperative nomogram predicting the 10-year probability of prostate cancer recurrence after radical prostatectomy. J Natl Cancer Inst 2006;98:715-7. htrps://doi.org/10.1093/inci/dij190

7. Ward JF, Blute ML, Slezak J, et al. The long-term clinical impact of biochemical recurrence of prostate cancer 5 or more years after radical prostatectomy. J Urol 2003;170:1872-6. https://doi.org/10.1097/01. ju.0000091876.13656.2e

8. Chism DB, Hanlon AL, Horwitz EM, et al. A comparison of the single and double factor high-risk models for risk assignment of prostate cancer treated with 3D conformal radiotherapy. Int I Radiat Oncol Biol Phys 2004;59:380-5. https://doi.org/10.1016/i.i.ipobp.2003.10.059

9. Ost P, Jereczek-Fossa BA, As NV, et al. Progression-free survival following stereotactic body radiotherapy for oligometastatic prostate cancer treatment-naive recurrence: A multi-institutional analysis. Eur Urol 2016;69:9-12. https://doi.org/10.1016/i.eururo.2015.07.004

10. Ost P, Bossi A, Decaestecker $K$, et al. Metastasis-directed therapy of regional and distant recurrences after curative treatment of prostate cancer: A systematic review of the literature. Eur Urol 2015;67:852-63. https://doi.org/10.1016/i.eururo.2014.09.004

11. Pasqualetti F, Panichi $M$, Sainato A, et al. [18F]Choline PET/CT and stereotactic body radiotherapy on treatment decision making of oligometastatic prostate cancer patients: Preliminary results. Radiat Oncol 2016;11:9. https://doi.org/10.1186/sl3014-016-0586-x

12. Kane $\mathrm{CJ}$, Amling $\mathrm{CL}$, Johnstone $\mathrm{PA}$, et al. Limited value of bone scintigraphy and computed tomography in assessing biochemical failure after radical prostatectomy. Urology 2003;61:607-11. https://doi.org/10.1016/S0090-4295(02)02411-1

13. Gomez P, Manoharan M, Kim SS, et al. Radionuclide bone scintigraphy in patients with biochemical recurrence after radical prostatectomy: When is it indicated? BJU Int 2004;94:299-302. https://doi.org/10.1111/i.1464-410X.2004.04927.x

14. Beresford MJ, Gillatt D, Benson RJ, et al. A systematic review of the role of imaging before salvage radiotherapy for post-prostatectomy biochemical recurrence. Clin Oncol (R Coll Radiol) 2010;22:46-55. https://doi.org/10.1016/i.lon.2009.10.015

15. Rouviere 0, Vitry T, Lyonnet D. Imaging of prostate cancer local recurrences: Why and how? Eur Radiol 2010;20:1254-66. https://doi.org/10.1007/s00330-009-1647-4

16. Vali R, Loid W, Pirich C, et al. Imaging of prostate cancer with PET/CT using 18F-fluorocholine. Am J Nucl Med Mol Imaging 2015;5:96-108.

17. Ramirez de Molina A, Rodriguez-Gonzalez A, Gutierrez $R$, et al. Overexpression of choline kinase is a frequent feature in human tumour-derived cell lines and in lung, prostate, and colorectal human cancers. Biochem Biophys Res Commun 2002;296:580-3. https://doi.org/10.1016/S0006-291X(02)00920-8
18. Umbehr MH, Muntener M, Hany T, et al. The role of 11 C-choline and 18F-fluorocholine positron emission tomography (PET) and PET/CT in prostate cancer: A systematic review and meta-analysis. Eur Urol 2013;64:106-17. https://doi.org/10.1016/i.eururo.2013.04.019

19. Leiblich A, Stevens D, Sooriakumaran P. The utility of molecular imaging in prostate cancer. Curr Urol Rep 2016;17:26. https://doi.org/10.1007/s1 1934-015-0573-z

20. Beheshti M, Imamovic L, Broinger $\mathrm{G}$, et al. $18 \mathrm{~F}$ choline PET/CT in the preoperative staging of prostate cancer in patients with intermediate or high risk of extracapsular disease: A prospective study of 130 patients. Radiology 2010;254:925-33. https://doi.org/10.1148/radiol.09090413

21. Kiolhede $\mathrm{H}$, Ahlgren $\mathrm{G}$, Almquist $\mathrm{H}$, et al. 18F-choline PET/CT for early detection of metastases in biochemical recurrence following radical prostatectomy. World J Urol 2015;33:1749-52. https://doi.org/10.1007/s00345-015-1547-y

22. Evangelista $\mathrm{L}$, Cimitan $\mathrm{M}$, Zattoni $\mathrm{F}$, et al. Comparison between conventional imaging (abdominal-pelvic computed tomography and bone scan) and [18F]choline positron emission tomography/computed tomography imaging for the initial staging of patients with intermediate- to high-risk prostate cancer: A retrospective analysis. Scand J Urol 2015;49:345-53. https://doi.org/10.3109/21681805.2015.1005665

23. Soyka JD, Muster MA, Schmid DT, et al. Clinical impact of 18F-choline PET/CT in patients with recurrent prostate cancer. Eur I Nucl Med Mol Imaging 2012;39:936-43. https://doi.org/10.1007/s00259012-2083-2

24. Goldstein J, Even-Sapir E, Ben-Haim S, et al. Does choline PET/CT change the management of prostate cancer patients with biochemical failure? Am J Clin Oncol 2014. [Epub ahead of print]. https://doi.org/10.1097/COC.0000000000000139

25. D'Angelillo RM, Sciuto R, Ramella S, et al. 18F-choline positron emission tomography/computed tomography-driven high-dose salvage radiation therapy in patients with biochemical progression after radical prostatectomy: Feasibility study in 60 patients. Int I Radiat Oncol Biol Phys 2014;90:296-302. https://doi.org/10.1016/i.ijrobp.2014.05.050

26. Heidenreich A, Bastian PJ, Bellmunt J, et al. EAU guidelines on prostate cancer. Part 2: Treatment of advanced, relapsing, and castration-resistant prostate cancer. Eur Urol 2014;65:467-79. https://doi.org/10.1016/i.eururo.2013.11.002

27. Rodado-Marina S, Coronado-Poggio M, Garcia-Vicente AM, et al. Clinical utility of 18F-fluorocholine positronemission tomography/computed tomography (PET/CT) in biochemical relapse of prostate cancer after radical treatment: Results of a multicentre study. BJU Int 2015;115:874-83. https://doi.org/10.1111/ bju. 12953

28. Cimitan M, Bortolus R, Morassut S, et al. [18F] fluorocholine PET/CT imaging for the detection of recurrent prostate cancer at PSA relapse: Experience in 100 consecutive patients. Eur J Nucl Med Mol Imaging 2006;33:1387-98. htrps://doi.org/10.1007/s00259-006-0150-2

29. Schillaci 0, Calabria F, Tavolozza M, et al. Influence of PSA, PSA velocity, and PSA doubling time on contrast-enhanced 18F-choline PET/CT detection rate in patients with rising PSA after radical prostatectomy. Eur J Nucl Med Mol Imaging 2012;39:589-96. https://doi.org/10.1007/s00259-011-2030-7

30. Cimitan $M$, Evangelista $L$, Hodolic $M$, et al. Gleason score at diagnosis predicts the rate of detection of 18F-choline PET/CT performed when biochemical evidence indicates recurrence of prostate cancer: Experience with 1000 patients. J Nucl Med 2015;56:209-15. https://doi.org/10.2967/ jnumed.114.141887

31. Chondrogiannis S, Marzola MC, Ferretti A, et al. Is the detection rate of 18F-choline PET/CT influenced by androgen-deprivation therapy? Eur J Nucl Med Mol Imaging 2014;41:1293-300. https://doi.org/10.1007/s00259-014-2720-z

32. Linder BJ, Kawashima A, Woodrum DA, et al. Early localization of recurrent prostate cancer after prostatectomy by endorectal coil magnetic resonance imaging. Can I Urol 2014;21:7283-9.

33. Kitaijma K, Murphy RC, Nathan MA, et al. Detection of recurrent prostate cancer after radical prostatectomy: Comparison of 11C-choline PET/CT with pelvic multiparametric MR imaging with endorectal coil. J Nucl Med 2014:55:223-32. https://doi.org/10.2967/inumed.113.123018

34. Bluemel C, Krebs M, Polat B, et al. 68Ga-PSMA-PET/CT in patients with biochemical prostate cancer recurrence and negative 18F-Choline-PET/CT. Clin Nucl Med 2016;41:515-21. https://doi.org/10.1097/ RLU.0000000000001197

35. Afshar-Oromieh A, Avtzi E, Giesel FL, et al. The diagnostic value of PET/CT imaging with the 68Ga-labelled PSMA ligand HBED-CC in the diagnosis of recurrent prostate cancer. Eur I Nucl Med Mol Imaging 2015;42:197-209. https://doi.org/10.1007/s00259-014-2949-6

Correspondence: Dr. Simon Gauvin, Department of Radiology, Jewish General Hospital, McGill University Health Centre, Montreal, QC, Canada; simon.gauvin@mail.mcgill.ca 